\title{
Educational Process in Higher Education Institutions in the Context of the COVID-19 Pandemic
}

\author{
Victor Boer, Sergei Andreitso, ${ }^{*}$ and Irina Timofeeva \\ Saint-Petersburg State University of Aerospace Instrumentation, Saint-Petersburg, Russia
}

\begin{abstract}
In 2020, almost all nations face a pandemic of COVID-19 coronavirus infection, including Russia. This virus has affected all spheres of social life, not excluding the field of education, and has required radical changes. The COVID-19 pandemic has given a strong impetus to the transition to a new education format, so students in higher education institutions have moved to a distance-learning format. With the transition to a new format, educational institutions had to face many difficulties, mainly the lack of experience and practice of mass introduction of remote access technologies to provide and receive educational services. At the same time, tremendous work has been carried out in Russia to amend the existing legislation on education, improve methods of regulating and controlling the educational process and the quality of education
\end{abstract}

\section{Introduction}

The sphere of higher education, compared with other levels of education in Russia, was, in our opinion, the most resistant to the pandemic. Universities literally moved the educational process to a distance learning format right away. Here it is important to note that, unfortunately, not all higher education institutions turned out to be ready for such a transition and were able to provide the same educational process as if they were providing it within the institution's walls. In this sense, the most problematic were technical equipment and stable Internet, which, in fact, significantly reduced and affected the quality of the educational process.

The authors of the article proceed from the hypothesis that introducing several restrictions in higher education institutions in the context of the COVID-19 pandemic has created a set of problems that need to be solved.

The authors conducted a study of the problems of implementing educational programs under the COVID-19 pandemic conditions. A feature of the approach was a separate analysis of different groups (technical staff, students, teachers, supervisors).

The study resulted in several recommendations to improve the legal regulation of educational activities in the context of the COVID-19 pandemic. The results of the study

\footnotetext{
* Corresponding author: andreytso@mail.ru
} 
were tested in the activities of the Faculty of Law of St. Petersburg State University of Aerospace Instrumentation (SUAI).

\section{Materials and Methods}

The study used statistics from the Ministry of Science and Higher Education of the Russian Federation, the Federal State Statistics Service of the Russian Federation, the Ministry of Health of the Russian Federation, analyzed normative legal acts (Constitution of the Russian Federation, Convention for the Protection of Human Rights and Fundamental Freedoms) practices of educational organizations.

Focus interviews were conducted (Lebedev, 2010) with teachers and students studying law in St. Petersburg.

There were three "blocks" of questions:

- learning outcomes and effectiveness in a pandemic;

- evaluation of current and new methodologies related to the limitations of the pandemic;

- proposals for improving the educational process.

The survey (20 respondents) was conducted by personal interview or by obtaining questionnaires filled out by the experts.

The results after processing (a generalization of positions, development of final recommendations, addressed to the authorities and educational organizations) were transferred to the educational authorities, are used in the educational process.

The advantage of this method was to obtain the positions of the expert community and students in the context of a single region, a major educational center - St. Petersburg.

\section{Results}

Challenges for education in a pandemic. The problem of technical equipment of the educational process implemented remotely is, for example, the lack of teachers' ability to organize a full-fledged workplace at home; the lack of students' computer/laptop, because the vast majority of educational process participants used smartphones, and they limit some functions (capabilities), compared to computer/laptop and all of this was affected by the problems of limiting the volume of Internet traffic and the performance of the Internet channel. Along with this problem, the problem of material and resource endowment also arose. Software failures, freezes, and errors in the work of websites, periodic problems with accessibility - almost all educational web resources in the spring of 2020, i.e. during the quarantine declared by the state, were not ready for mass visits by users. This led to the fact that several necessary informative and methodologically competent online educational platforms were unavailable for use when the educational process was predominantly in a distance learning format.

It should be understood that not all subjects can be taught remotely using information and education technologies. For example, distance education in medical specialization, engineering, and other technical and creative fields and professions has proved to be incredibly difficult and, as such, the consequences, such as low quality of education during the pandemic and low knowledge and skills of the learners during this period cannot be ruled out.

Distance learning format: pros and cons. In distance education, during the COVID-19 pandemic, rapid decisions were made by the management of higher education institutions to reduce the negative impact of the pandemic on the higher education system. Among them, the most popular are the following: use of the online format in education; universal shift to 
distance learning; use of alternative methods of education; improvement of technical training of teachers; application of methods of continuous education assessment.

One thing is clear: it is impossible to imagine education without a distance format at a time of pandemics. So the very first thing educational institutions in many states did when their governments declared "lockdowns", due to the epidemic, is that they introduced a widespread distance format in their territories. And Russia is not an exception.

One of the most common types of distance learning has become the online learning format. Zoom, Skype, and other educational platforms (digital platforms or LMS) have literally become the "salvation" for many universities and other higher education institutions.

It should be admitted that higher education institutions in Russia turned out to be more ready for such a transition than schools and educational institutions of secondary vocational education. Many universities have long developed video courses for lectures and practical classes taught in this format, and there was already a practice of using the online learning format. And, for example, schools and secondary vocational institutions have had to respond swiftly to changes related to the COVID-19 pandemic and distance learning.

Alternative educational methods that have also proved successful in the distance learning format were: adaptive learning; interactive and experiential approaches; methods of self-learning and strengthening the role of independent work; team learning; blended learning format (online-offline mode); simulation and game techniques.

The impact of the pandemic on the education system is significant not only because the pandemic has forced the search for new approaches to learning. It also showed the importance of the teaching profession and its role in the educational process, as well as the importance of their technical training. Unfortunately, many teachers were not prepared to move to alternative learning formats because they did not have the appropriate knowledge and skills to use the necessary technology and software to use the learning platforms and organize lessons in the new format. All this led to the need for additional training and operational assistance for the teaching staff so that they could gain the necessary technical skills more quickly.

Another important challenge facing higher education institutions during the COVID-19 pandemic is the need to review assessment methods. Questions have arisen: how to conduct examinations remotely; how to assess control and defend graduate qualification works, including master's thesis? And all these questions were urgently needed to be answered by educational institutions.

For qualitative control of current knowledge, most educational institutions during the pandemic chose the method of continuous assessment, i.e., the skills and abilities acquired by trainees during lectures and practical classes were checked immediately. And tests and examinations only confirmed the level of knowledge received.

The process of the state final and interim certification in the distance mode was complicated by biased assessment. Higher education institutions had the right to cancel the state exam if the standard allowed the final attestation in the form of a graduate qualification work. However, almost all educational institutions retained both types of final attestation of graduates: state examination and defense of the graduate qualification work.

The problems of organizing the educational process in higher educational institutions in the context of the coronavirus pandemic were, of course, there. Most of these problems were formed as a direct consequence of the massive format of distance learning in higher education institutions, introduced as a forced and, in general, unexpected measure.

The impact of the pandemic on higher education in Russia is certainly as great as in other countries. Our state responded quickly enough to the external threat and introduced a widespread "lockdown" and distance learning format of the educational process. This has led to both positive and negative consequences. On the positive side, distance learning has a 
future in Russia. This is especially true for universities, which have quickly adapted to the new conditions and moved their students to an online format. Education received a boost during the pandemic in Russia, allowing for full implementation of distance learning at all levels of education. Not only higher education institutions have successfully coped with this, but also schools, as well as secondary vocational institutions, have revised their curricula and started actively using new methods of distance learning. The negative impacts of the pandemic on higher education in the Russian Federation are much greater. Despite the positive aspects of distance education, there are significant disadvantages that cannot yet be translated into pluses. Learning in higher education institutions is based on a close relationship between a teacher and a learner. Without interaction with a higher education teacher, many academic disciplines remain misunderstood and students lose motivation in mastering the material independently. Professional educational institutions train specialists and bachelors, who need practice and technical experience, and it is impossible to obtain it by distance learning methods today. In general, education during the pandemic in Russia, as well as all over the world, has felt a significant decline. The situation can be remedied by the following measures: introduction of alternative methods of teaching in all educational institutions; adoption of non-standard solutions that can increase the share of practical lessons; return to the usual offline format. Looking only at the economic impact of the pandemic, UNESCO estimates that about 23.8 million more children and youth (from preschool to tertiary education) could drop out of school or find themselves without access to education in the next year [3]. It is clear that in high-income countries between 80 and 85 percent of students are enrolled in distance education, while in low-income countries the figure drops to less than 50 percent. This deficiency is largely due to the fact that, first, during the conditioned COVID-19 crisis, approximately 40 percent of the poorest countries were unable to support students at risk [4] and, as a result, some populations had limited access to such basic household services like electricity supply; secondly, the lack of technological infrastructure, and, thirdly, the low level of digital literacy among students and teaching staff of an educational institution of higher education.

\section{Discussion}

Incoming academic mobility flows to countries that have traditionally hosted international students from all over the world are projected to decrease in the coming year: UK, USA, Canada, New Zealand, Australia. And if this is indeed the case, it is likely that these flows can be redirected to countries that offer high-quality higher education but are much closer geographically with the adequate cost of educational services or availability of appropriate financial support mechanisms (grants, scholarships, educational loans). Experts note that the decline in higher education institutions' revenues from fewer foreign students will be an irretrievable loss for many universities, and many educational institutions, especially those from developing countries, will have a very difficult time. At the same time, we should expect a wave of interest in countries such as South Korea, China, and Russia. As statistics show, these countries have been the most effective in coping with the spread of the pandemic and the proportion of COVID-19 deaths per 100,000 people was less than $1 \%$. Experts agree that in the near future this aspect will become one of the decisive ones when choosing a country to study in.

In the context of the pandemic, it was necessary to pay attention to the reaction of society to such situations [5] (A. Perciaccante, M. Malacrea, A. Coralli, S. Donell). Various works related to "pandemic waves" and the response to them were analyzed (Aline Bourdin, Jennifer Dotta-Celio, Anne Niquille, Jérôme Berger) [6]. The issue of vaccine confidence has arisen with continued restrictions and the start of the vaccination campaign (Majdi M Sabahelzain, Kenneth Hartigan-Go, Heidi Larson) [8]. 


\section{Conclusion}

The COVID-19 pandemic demonstrated both the positives and the challenges of organizing the educational process in a distance learning format. According to S. Kosaretsky, Director of the Center for General and Additional Education of the National Research University Higher School of Economics, after the end of the quarantine, the mechanisms of remote classes will be used more widely than before and it will become an alternative to the regular mode of education. During the quarantine period within the distance learning format, higher education institutions were able to fully evaluate the effectiveness of the proposed digital technologies, determine their needs for further technological modernization, and, if necessary, think through and decide on the organization of professional development, retraining and additional training of teaching staff in information technology in science and education.

Despite the above challenges, the pandemic has had a positive impact on the internationalization of education. This was expressed, first of all, in the intensive work of educational institutions of higher education in forming new formats of interaction with partners, in increasing virtual mobility, and strengthening the role of educational institutions. Many Russian higher education institutions, in addition to the use of modern technologies in an online format in the educational process, have created an online community of students, teachers, administrators, which has helped to improve the quality of education and reduce the stress of social isolation in the learning environment for international students.

Legal regulation of distance education. Russia, like many countries of the RomanoGermanic legal system, was forced to introduce and adopt as soon as possible changes and amendments to the legislation on education, providing for the transition of educational institutions of higher education to the online or distance format, including the conduct of state final certification and entrance examinations in the same format. The transition of higher education institutions to the distance learning format of the educational process is due to the fact that Russia has adopted the relevant amendments to the law "On Education in the Russian Federation" concerning the approval of distance learning on a par with the traditional format of education, including in the areas and specialties designated in the federal state educational standards, for which training is impossible exclusively in distance format. The legal status of distance education was also established (M.S. Oboronin) [10] and the definition of "distance education" and "the use of information and telecommunication networks to transmit certain data through communication channels, the interaction of students and teachers" was given, which was amended accordingly in the Federal Law "On Education in the Russian Federation".

Internationalization of Education in the Context of COVID-19. The pandemic has influenced the internationalization of education at the international level in higher education. The pandemic has made major changes in the plans of potential international students with a desire to pursue higher education abroad. At the same time, despite the fact that their plans have changed, interest in higher education abroad has remained, so educational institutions of higher education have simplified the admission procedure for foreign applicants during the pandemic. The vast majority of tertiary education institutions were faced with organizing logistics and educational support for international students staying in the country of study and/or traveling home during the pandemic; student and teacher exchange programs have been suspended. Higher education institutions began to look for new forms of attracting foreign students and organizing the educational process for them. The problem was the establishment and development of partnerships of higher education institutions to design and launch joint educational programs that would provide 
issuing two diplomas or one joint diploma; funding of research projects, studying in the master's degree program.

\section{References}

1. Constitution of the Russian Federation, Official Internet portal of legal information, http://pravo.gov.ru/

2. Convention for the Protection of Human Rights and Fundamental Freedoms Legislative Assembly of the Russian Federation, http://www.constitution.ru/en/10003000-03.htm

3. UNESCO, «COVID-19 Education Response: How many students are at risk of not returning to school? http://tcg.uis.unesco.org/survey-education-covid-school-closures

4. UNESCO, Global Education Monitoring (GEM) Report, 2020: Inclusion and education: all means, https://unesdoc. unesco.org/ark:/48223/pf0000373718

5. A. Perciaccante, M. Malacrea, A. Coralli, S. Donell Literature "magistra vitae": What literature teaches about society's reactions to pandemic outbreaks Ethics Med Public Health. (Published online, 2021)

6. A. Bourdin, J. Dotta-Celio, A. Niquille, J.Berger, Sciencedirect, 10, 1016 (2021)

7. M. M. Sabahelzain, K. Hartigan-Go, H. Larson, Sciencedirect, 10 (2021)

8. P.A. Lebedev, Sociology: methodology, methods, mathematical modeling, 31, 92 (2010)

9. M.S. Oboronin, Servis v Rossii i za rubezhom, 14(5), 153 (2020)

10. M.YU. Arzhanova, L.V. Baryshnikova, V.A. Zavarykina, O.V. Nagornov, M. Perfil'eva, Analiticheskij material, 8 (2020) 